\title{
Erratum to: Critically Underdeveloped Left Heart Morphology Associated with Prematurity and Low Birth Weight: Conditional Staged Rehabilitation Towards Biventricular Repair and Time- Related Growth of Left Heart Structures
}

Fareed Ahmad $^{1} \cdot$ Robert Mangano $^{1} \cdot$ Shirah Shore $^{1} \cdot$ Anastasios Polimenakos $^{2}$

Published online: 31 July 2017

(C) Springer Science+Business Media, LLC 2017

\section{Erratum to: Pediatr Cardiol}

\section{DOI 10.1007/s00246-017-1644-3}

The original version of this article unfortunately contained a mistake.

The affiliation of the author Anastasios Polimenakos has been mentioned incorrectly in the article as:
"Janet Weis Children hospital, Geisinger Health System, 100, North Academy Avenue, Danville, PA 17822, USA"

The correct affiliation is given below

Division of Pediatric Cardiothoracic Surgery, Children's Hospital of Georgia, Medical College of Georgia, 1120 15th Street BAA 8300 Augusta, GA 30912, USA

The online version of the original article can be found under doi:10.1007/s00246-017-1644-3.

Fareed Ahmad

fahmad1@geisinger.edu

1 Janet Weis Children hospital, Geisinger Health System, 100, North Academy Avenue, Danville, PA 17822, USA

2 Division of Pediatric Cardiothoracic Surgery, Children's Hospital of Georgia, Medical College of Georgia, 1120 15th Street BAA 8300, Augusta, GA 30912, USA 